\title{
The Status of Thermophotovoltaic Energy Conversion Technology at Lockheed Martin Corporation
}

EJ Brown, PF Baldasaro, SR Burger, LR Danielson, DM DePoy, JM Dolatowski, PM Fourspring, GJ Nichols, WF Topper, and TD Rahmlow

This report was prepared as an account of work sponsored by the United States Government. Neither the United States, nor the United States Department of Energy, nor any of their employees, nor any of their contractors, subcontractors, or their employees, makes any warranty, express or implied, or assumes any legal liability or responsibility for the accuracy, completeness or usefulness of any information, apparatus, product or process disclosed, or represents that its use would not infringe privately owned rights. 


\title{
The Status of Thermophotovoltaic Energy Conversion Technology at Lockheed Martin Corp.
}

\author{
EJ Brown ${ }^{*}$, PF Baldasaro ${ }^{\dagger}$, SR Burger ${ }^{\ddagger}$, LR Danielson $^{\S}$, DM DePoy ${ }^{* *}$, JM Dolatowski ${ }^{\dagger \dagger}$, \\ PM Fourspring ${ }^{\ddagger \ddagger}$, GJ Nichols ${ }^{\S \S}$, WF Topper** \\ Lockheed Martin Corp. \\ TD Rahmlow ${ }^{\dagger \dagger}$ \\ Rugate Technologies, Inc.
}

\begin{abstract}
In a thermophotovoltaic (TPV) energy conversion system, a heated surface radiates in the mid-infrared range onto photocells which are sensitive at these energies. Part of the absorbed energy is converted into electric output. Conversion efficiency is maximized by reducing the absorption of non-convertible energy with some form of spectral control. In a TPV system, many technology options exist. Our development efforts have concentrated on flat-plate geometries with greybody radiators, front surface tandem filters and a multi-chip module (MCM) approach that allows selective fabrication processes to match cell performance. Recently, we discontinued development of GaInAsSb quaternary cell semiconductor material in favor of ternary GaInAs material. In our last publication (Ref. 1), the authors reported conversion efficiencies of about $20 \%$ (radiator $950^{\circ} \mathrm{C}$, cells $22^{\circ} \mathrm{C}$ ) for small modules $\left(1-4 \mathrm{~cm}^{2}\right.$ ) tested in a prototypic cavity test environment. Recently, we have achieved measured conversion efficiencies of about $12.5 \%$ in larger $\left(\sim 100 \mathrm{~cm}^{2}\right)$ test arrays. The efficiency reduction in the larger arrays was probably due to quality and variation of the cells as well as non-uniform illumination from the hot radiator to the cold plate. Modules in these tests used GaInAsSb cells with $0.52 \mathrm{eV}$ bandgap and front surface filters for spectral control. This paper provides details of the individual system components and the rationale for our technical decisions. It also describes the measurement techniques used to record these efficiencies.
\end{abstract}

\section{Summary}

Lockheed Martin has been developing thermophotovoltaic (TPV) direct energy conversion for about ten years. Significant progress has been achieved in four key areas:

1. Conversion Efficiency -conversion efficiency has made dramatic improvements since 1995 as shown in Figure 1. The latest small-scale modules are about 20\% efficient and larger arrays achieve efficiencies of about $12.5 \%$ (hot side radiator at $950^{\circ} \mathrm{C}$, cells near room temperature).

2. Spectral Control - efforts to limit the parasitic absorption of non-convertible (below cell bandgap) photons have concentrated on front surface selective filters. The most recent tandem filters have spectral efficiency of $83 \%$ (Figure 2).

3. Prototypic Testing - we have developed two test systems to carry out direct measurements of integrated TPV systems under prototypic conditions: for small modules $\left(1-4 \mathrm{~cm}^{2}\right)$, we use the

\footnotetext{
* EJ Brown, Sr. Engineer, MS 103, PO Box 1072, Schenectady, NY 12301; (518) 395-7045, email browne@kapl.gov

${ }^{\dagger}$ PF Baldasaro, Advisory Scientist, MS 103, PO Box 1072, Schenectady, NY 12301; (518) 395-6711

‡ SR Burger, Sr. Engineer, MS 103, PO Box 1072, Schenectady, NY 12301; (518) 395-6817

$\S$ LR Danielson, Sr. Scientist, MS 103, PO Box 1072, Schenectady, NY 12301; (518) 395-6854

** DM DePoy, Lead Engineer, MS 103, PO Box 1072, Schenectady, NY 12301; (518) 395-4412

†† JM Dolatowski, Engineer, MS 103, PO Box 1072, Schenectady, NY 12301; (518) 395-7534

㧊 PM Fourspring, Sr. Engineer, MS 103, PO Box 1072, Schenectady, NY 12301; (518) 395-6563

$\S \S$ GJ Nichols, Lead Engineer, MS 103, PO Box 1072, Schenectady, NY 12301; (518) 395-4425

*** WF Topper, Sr. Engineer, MS 103, PO Box 1072, Schenectady, NY 12301; (518) 395-7577

†† TD Rahmlow , 353 Christian Street Oxford, CT 06478 (203) 267-3154; email info@rugate.com
} 
Photonic Cavity Test (PCT) system (Figure 3a). For larger arrays $\left(\sim 100 \mathrm{~cm}^{2}\right)$, we use the Small Array Test (SAT) system (Figure 3b). Both systems incorporate the geometric, electrical, optical and optical behavior typical of a TPV photonic cavity. All measured efficiency results presented here are determined from experiments carried out in one of these systems.

4. Integrated System Modeling - in-house computer models were developed and extensively benchmarked using earlier results obtained in the PCT system (Figure 4).

\section{Background}

In a TPV energy conversion system, a heated surface radiates to light-sensitive cells which convert a portion of the incident energy to electric power as shown in Figure 5. Cells can only generate electric power from photons with energy greater than the bandgap of the material (Figure 6). If a photon with energy less than the bandgap is absorbed by the cell, it is converted to waste heat which lowers the overall conversion efficiency. Because of materials considerations, the radiant surface is usually limited to temperatures between $900-1200^{\circ} \mathrm{C}$.

TPV was first proposed in the 1960's (Ref. 2,3,4). Interest waned, however, because the commonly available semiconductor (silicon) had a relatively high bandgap (1.1 eV). Assuming a blackbody radiator at $950^{\circ} \mathrm{C}$, only $0.6 \%$ of the radiant energy is potentially convertible to electric power. Interest in TPV was revived in the 1990's with the development of compound semiconductors which made possible high quality semiconductors with lower bandgaps. For example, a GaSb cell with a bandgap of $0.73 \mathrm{eV}$, can convert $8.3 \%$ of the radiant energy from a $950^{\circ} \mathrm{C}$ radiator. For semiconductors with lower bandgaps, an even larger fraction of the radiant spectrum is convertible to electric output.

After the development of lower bandgap semiconductors, the key technical challenge was the creation of a highly effective spectral control system. Unlike a photovoltaic system, TPV can make significant improvements in efficiency by reducing absorption of non-convertible photons via selective emission or reflection schemes.

\section{System Efficiency}

As noted in Ref. 1, the overall system conversion efficiency can be viewed as the product of separate component performance factors. For our small-scale $\left(1-4 \mathrm{~cm}^{2}\right)$ modules tested in the PCT system, three factors describe the system performance:

$$
\eta_{\mathrm{TPV}}=\eta_{\text {cell }} * \eta_{\text {spectral }} * \eta_{\text {mod }} \quad \text { [equ. 1] }
$$

where $\eta_{\text {cell }}$ and $\eta_{\text {spectral }}$ are the separate performance factors for the cells and (for Lockheed Martin system) front surface spectral control filters. $\eta_{\text {mod }}$ is the factor to account for parasitic photon absorption in gold conduction structures, small gaps, etc. associated with module fabrication. For our larger modules tested in the SAT system $\left(\sim 100 \mathrm{~cm}^{2}\right)$, other effects must be considered:

Factor for parasitic photon absorption in cracks between filter segments

Factor for parasitic photon absorption in cold-side structural members

Factor for conductive losses to cold-side structures

Factor for network losses; reduction of electric output due to mismatched cells

Factor for non-uniform illumination from the hot radiator

Factor for reduced cell quality

These effects are grouped into a single term, $\eta_{\text {sys }}$, which is included in equation 2 , below:

$$
\eta_{\mathrm{TPV}}=\eta_{\mathrm{cell}} * \eta_{\mathrm{spectral}} * \eta_{\mathrm{mod}} * \eta_{\mathrm{sys}} \quad \text { [equ. 2] }
$$


These definitions of efficiency are the implicit bases for all measurements carried out in our test systems and reported here. Extrapolating results reported here to even larger systems that could include lifetime degradation effects and possible combustion losses would require the application of other factors to accurately model overall system efficiency. Some of these are:

Factor for inefficiency of the combustion system (burner/ recuperator, if applicable)

Factor for effect of an inert cover gas (if applicable)

Factor for power required to run auxiliary systems (air blowers, fuel pumps)

Factor for lifetime system degradation)

Factor for thermal losses from the heat source

It is noted that, while this formulation is a convenient method to conceptualize TPV module behavior, it can be misleading because it appears that the separate factors are independent. In fact, this is often not the case. Efforts to increase $\eta_{\text {mod }}$ by reducing the size of the gold conduction structures, for example, can increase the series resistance which would decrease the cell efficiency through the fill factor. Similarly, if $\eta_{\text {spectral }}$ is increased at the expense of short circuit current, a secondary effect will also reduce the open circuit voltage and, therefore, module efficiency as well. This interdependency of efficiency terms is a major reason why reliable measurements of TPV efficiency must be carried out on an integrated module and not synthesized from separate measurements on the individual components.

\section{System Technology Options}

An integrated TPV system is comprised of five critical components; for each component, there are a number of technology options. The choices made will be governed by system performance trade-off's and the specific criteria to which the system is designed. For example, low bandgap cells tend to be quite expensive but they can yield a significantly higher surface power density. The matrix of design elements and technology options produces a large number of possible system configurations.

Table 1 (below) describes the system elements, technology options and highlights the current choices made by Lockheed Martin in designing the systems described in the remainder of this paper.

TABLE 1 - Technology Options for an Integrated TPV Energy Conversion System (boldface entries indicate technology options incorporated in Lockheed Martin system)

\begin{tabular}{|c|c|c|c|c|}
\hline $\begin{array}{c}\text { SYSTEM } \\
\text { GEOMETRY }\end{array}$ & RADIATOR & CELLS & $\begin{array}{l}\text { SPECTRAL } \\
\text { CONTROL }\end{array}$ & NETWORK \\
\hline $\begin{array}{l}\text { Flat Plate } \\
\text { Cylindrical }\end{array}$ & $\begin{array}{l}\text { Grey Body } \\
\text { Selective Radiator } \\
\text { Spectral Radiator } \\
\text { Textured Surface }\end{array}$ & $\begin{array}{c}\text { Silicon } \\
\text { Binary } \\
\underline{\text { Ternary }} \\
\underline{\text { Quaternary* }} \\
\text { High Bandgap } \\
\underline{\text { Low Bandgap }} \\
\begin{array}{c}\text { *LM has recently } \\
\text { switched to }\end{array} \\
\begin{array}{c}\text { GaInAs as primary } \\
\text { material option }\end{array}\end{array}$ & $\begin{array}{c}\text { Radiator Treatment } \\
\text { - textured surface } \\
\text { - rare-earth oxides } \\
\text { - hot side filters } \\
\text { Front Surface Filter } \\
\text { - Interference } \\
\text { - Tandem } \\
\text { - Metal Dipole } \\
\text { Back Surface } \\
\text { Reflector }\end{array}$ & $\begin{array}{l}\text { *LM favors the MCM } \\
\text { option but is currently } \\
\text { evaluating MIM designs as } \\
\text { an alternative for GaInAs } \\
\text { cells }\end{array}$ \\
\hline
\end{tabular}




\section{TPV Cells}

In designing TPV cells, semiconductor material choice and bandgap selection is governed by the need to balance energy conversion efficiency and surface power density. For a given photonic energy spectrum, a lower bandgap cell material will release more electrons to be collected. However, lower bandgap cell materials have intrinsic properties that decrease their photon-to-electron conversion efficiency.

The process of selecting the optimum TPV cell bandgap material depends on a particular system's efficiency and power density requirements. Given a specific heat source temperature, cell temperature and spectral control efficiency, a cell bandgap versus TPV system efficiency ( $\left.\eta_{\text {TPV }}\right)$ and power density relationship can be determined as shown in Figure 7. A clear trade-off exists between power density and system efficiency.

Terrestrial heat source TPV systems require cell bandgaps in the range of 0.4 to $0.72 \mathrm{eV}$. Group III-V semiconductor materials such as the gallium-indium-arsenide (GaInAs), gallium-indium-arsenideantimonide (GaInAsSb), indium-arsenide-phosphide-antimonide (InAsPSb), and gallium antimonide (GaSb) alloys are attractive candidates since they are direct bandgap materials and can be grown on commercially available substrates.

The cell efficiency, $\eta_{\text {cell }}$, is the ratio of the electric power output to the above-bandgap energy absorbed in active areas of the cell. It is actually the product of four other factors:

$$
\eta_{\text {cell }}=\text { Fo } * \text { QEint } *[\mathrm{e} *(\mathrm{Voc} / \mathrm{Eg})] * \mathrm{FF} \quad \text { [equ. 3] }
$$

where: Fo is the penalty term to account for the fact that photons with energy significantly above the semiconductor bandgap will generate waste heat with the excess energy

QEint is the average internal quantum efficiency, i.e. the probability that an absorbed photon will result in a charge carrier that is collected at the cell junction

$\left[\mathbf{e}^{*}(\mathbf{V o c} / \mathbf{E g})\right]$ is the product of the elementary electronic charge times the fraction of the bandgap achieved by the open circuit voltage generated by the cell

FF is the cell fill factor, i.e. the penalty paid because no cell can, at the same time produce the open circuit voltage and the short circuit current. FF is heavily dependent on the series resistance in the cell and connecting structures.

Until recently, we had been focusing on the GaInAsSb alloy system lattice matched to GaSb substrates. The GaInAsSb alloy composition can be varied to obtain an approximate bandgap range of 0.3 to $0.7 \mathrm{eV}$ (ref. 5). We were targeting a low-bandgap $(\sim 0.48 \mathrm{eV})$ material as having the highest potential to maximize power density while maintaining an achievable high efficiency. Figure 8 depicts the GaInAsSb TPV cell layers and metal contacts. The GaInAsSb cell is grown by organo-metallic vapor phase epitaxy (OMVPE) on commercially available n-type GaSb substrates.

Under prototypic conditions (as defined in this paper), the cell efficiency for our most advanced GaInAsSb cells is:

$$
\eta_{\text {cell }}=0.79 * 0.83 *[0.60] * 0.69=0.27
$$

A recent re-evaluation of our design criteria and the state of progress of the quaternary material resulted in a decision to "mothball" further development of GaInAsSb in favor of the ternary material, GaInAs grown on InP. The reasons for this decision are listed below:

1. Open circuit voltage limited to 320mvolts - theoretical predictions for GaInAsSb had been in the 350 mvolt range but we were unable to achieve this value.

2. Bandgap limited to $\sim 0.53 \mathrm{eV}$ - we had expected to achieve bandgaps as low as $0.48 \mathrm{eV}$ but our experience showed that phase separation due to a miscibility gap occurred when fabricating material below about $0.52 \mathrm{eV}$.

3. No benefit in Auger coefficient - analyses showed that expected advantages for GaInAsSb over GaInAs would not be achieved.

4. No power density advantage - experiments and further analyses indicated that, for a given bandgap, high power densities are achievable with GaInAs ternary material. Furthermore, 
high performance lattice mismatched GaInAs devices with bandgaps as low as $0.50 \mathrm{eV}$ may be achievable with further development.

Currently, the GaInAs ternary material is grown on semi insulating substrates which are suitable for the monolithicly interconnected module (MIM) device architecture. Lockheed Martin favors the use of large, separate cells (multi-chip module, MCM) which are interconnected with wire bonding techniques. Because this approach requires back surface electrical contact, three issues emerge:

1. We must demonstrate the ability to grow and process single cells with functional back surface reflectors (BSR's) to improve spectral control and to reduce radiative recombination losses.

2. We must demonstrate the ability to grow GaInAs ternary material on InP that is doped to levels high enough to reduce the total electrical series resistance to less than $1 \mathrm{mohm}$. Failure to do so will degrade the device fill factor.

3. We must show that the doping level in the InP substrate does not introduce significant freecarrier absorptions which would iimpact the performance of the BSR.

\section{Spectral Control}

Spectral control is a key technology for TPV direct energy conversion systems. As shown in Figure 6, for blackbody radiator at $950^{\circ} \mathrm{C}$ with $0.52 \mathrm{eV}$ bandgap cells, only $\sim 25 \%$ of the incident radiation can be converted to electricity. The remaining $\sim 75 \%$ of the incident radiation cannot be converted to electricity, and, therefore, would be parasitically absorbed if no steps were taken.

Lockheed Martin has favored selective front-surface filters for spectral control because, unlike special radiator techniques, they operate at about room temperature (Ref. 6). Furthermore, it is convenient to separate the spectral control function from the cell because this allows the optimization of each component separately. The goal for TPV spectral control is twofold:

1. Maximize TPV surface power density by maximizing transfer of convertible (high energy, above bandgap) photons from the radiator to the TPV cell.

2. Maximize TPV efficiency by minimizing transfer of non-convertible (low energy, below bandgap) photons from the radiator to the TPV cell.

Front surface spectral control performance is characterized by two key parameters: spectral efficiency and integrated above bandgap transmission efficiency. As shown in Equ. 4 and 5, spectral efficiency is a direct multiplier on system conversion efficiency. It is defined as the ratio of the above-bandgap power absorbed in the TPV cell (and filter) active area to the total power absorbed over the same area (Equ. 4). The integrated above-bandgap transmission of a filter (shown in Equ. 5) is proportional to the electrical output power density $\left(\mathrm{W} / \mathrm{cm}^{2}\right)$ of the TPV module. Integrated above-bandgap transmission is defined as the ratio of the electrical output power density from a TPV device with a filter to the electrical output power density that would be achieved with the same TPV device with a perfect anti-reflection coating (reflectivity $(\lambda, \theta)=0)$. 


$$
\eta_{\text {spectral }}=\frac{\int_{0}^{\frac{\pi}{2} \lambda g} \int_{0} \varepsilon_{\text {eff }}\left(\lambda, \theta, T_{\text {rad }}\right) \frac{T_{\text {filter }}(\lambda, \theta)}{1-R_{\text {filter }}(\lambda, \theta)} N\left(\lambda, T_{\text {rad }}\right) \sin \theta \cos \theta d \lambda d \theta}{\frac{\pi}{2} \int_{0}^{\infty} \int_{0} \varepsilon_{\text {eff }}\left(\lambda, \theta, T_{\text {rad }}\right) N\left(\lambda, T_{\text {rad }}\right) \sin \theta \cos \theta d \lambda d \theta}
$$

$$
\begin{aligned}
& \int_{0}^{\frac{\pi}{2}} \int_{0}^{g} \varepsilon_{\text {eff }}\left(\lambda, \theta, T_{\text {rad }}\right) \frac{T_{\text {filter }}(\lambda, \theta)}{1-R_{\text {filter }}(\lambda, \theta)} N\left(\lambda, T_{\text {rad }}\right) \sin \theta \cos \theta d \lambda d \theta \\
& \mathrm{T}_{>\mathrm{Eg}}=\frac{\frac{\pi}{2} \lambda g}{\int_{0} \int_{0}^{1} \varepsilon_{\text {rad }}\left(\lambda, \theta, T_{\text {rad }}\right) N\left(\lambda, T_{\text {rad }}\right) \sin \theta \cos \theta d \lambda d \theta}
\end{aligned}
$$

where:

$\mathrm{T}_{\text {filter }}(\lambda, \theta)$ is the filter Transmission versus wavelength and angle of incidence

$\mathrm{R}_{\text {filter }}(\lambda, \theta)$ is the filter Reflection versus wavelength and angle of incidence

$\lambda$ is wavelength

$\lambda_{\mathrm{g}}$ is the wavelength corresponding to the bandgap $\left(E_{g}\right)$ of the TPV device

$\mathrm{N}\left(\lambda, \mathrm{T}_{\mathrm{rad}}\right)$ is Planck's blackbody spectral distribution of emissive power

$\theta$ is the angle of incidence (polar angle) of incoming photons

$\mathrm{T}_{\text {rad }}$ is the radiator temperature

$\varepsilon_{\text {rad }}\left(\lambda, \theta, T_{\text {rad }}\right)$ is the radiator emissivity versus wavelength, angle and temperature

$\varepsilon_{\text {eff }}\left(\lambda, \theta, \mathrm{T}_{\mathrm{rad}}\right)$ is the effective cavity emissivity calculated from Equ. 6, below:

$$
\varepsilon_{\text {eff }}\left(\lambda, \theta, T_{\text {rad }}\right)=\frac{1}{\frac{1}{\varepsilon_{\text {rad }}\left(\lambda, \theta, T_{\text {rad }}\right)}+\frac{1}{1-R_{\text {filter }}(\lambda, \theta)}-1} \quad \text { [Equ.6] }
$$

It is important to note that, because the radiator emits isotropically and is very close to the TPV modules, photons are incident on the filter surface with a polar angular distribution as shown in Figure 9. The angle-of-incidence (AOI) distribution for parallel flat plate geometry peaks at (and is symmetric about) 45 degrees. Therefore, front surface filters should be designed for optimum performance at $45^{\circ} \mathrm{AOI}$ and with minimal sensitivity of filter performance to changes in AOI. Also, the angular characteristics of the filter $\left(\mathrm{T}_{\text {filter }}\right.$ and $\left.\mathrm{R}_{\text {filter }}\right)$ must be included in all performance modeling to achieve realistic results.

The front surface filter utilized in the system described in this paper is based on a tandem filter concept. As shown in Figure 10, the tandem filter concept is the combination of a plasma filter with an interference filter. The interference filter serves two purposes: first, it provides very high reflection of subbandgap photons in the 2.4 to $\sim 6$ micron range. Second, it "masks" a narrow absorption region ( 4 
microns) of the plasma filter. It is also worth noting that the interference filer can transition from highly transmissive to highly reflective over a very narrow ( 0.1 micron) range which improves spectral performance.

The plasma filter is necessary because it is difficult to extend the interference filter's reflective range past about $\sim 6$ microns without impacting the transmission of the above-bandgap photons. At $950^{\circ} \mathrm{C}$, about $17 \%$ of all radiant energy is emitted with a wavelength greater than 6 microns and the plasma filter is very effective at "recycling" this energy. Figure 11 shows how these two filters function together to produce a very effective spectral control technology.

Figure 2 shows the measured reflection versus wavelength our latest tandem filter at $45^{\circ} \mathrm{AOI}$. As defined in Equ. 4, the spectral efficiency of this filter (based on measured data including angle of incidence effects) is $\sim 83 \%$ and measured integrated above bandgap transmission of $\sim 79 \%$. Furthermore, the same codes used to design this filter can predict filter performance with a high degree of accuracy. Figure 2 also shows the measured performance of this filter design together with the pre-fabrication predictions. The predicted spectral efficiency factor was $84 \%$.

\section{Module Design \& Assembly and Electrical Networking Effects}

Module design and assembly affects the $\mathbf{O}_{\text {mod }}$ term (equ. 1,2 ) and the interaction of non-identical cells affects the $\mathrm{O}_{\text {sys }}$ term (equ. 2). Recent improvements in module fabrication techniques have improved $\mathrm{O}_{\text {mod }}$ from less than $70 \%$ to $>85 \%$. Figure 12 provides a sketch of a current TPV module design. Module performance improvements, together with a description of the module design and/or assembly techniques that produced the performance improvements, are summarized as follows:

1) Reduced parasitic absorption of above bandgap energy

Above bandgap energy is parasitically absorbed in non-active areas in the module including gold coated electrical interconnects and gaps between adjacent cells. The energy incident on these surfaces is not available to convert to electricity and becomes waste heat. A significant reduction in parasitic absorption was achieved by moving the electrical busbar from the center of the cell to the edge of the cell (Figure 12). This produced a 7\% increase in active area since the centerline busbar accounted for $10 \%$ of the cell area while the edge busbar reduced this to $3 \%$. The reduction in busbar area is possible since moving the busbar from the center to the edge of the cell essentially changed the busbar from a point contact to a line contact which increased cross-sectional area by an order-of-magnitude. In addition to this increase in active area, the edge busbar also allowed the thickness of the electrical interconnects to be reduced from 63um to $13 \mathrm{um}$. This low profile interconnect reduced the gap between adjacent cells, further reducing parasitic losses.

2) Improved electrical networking performance

An electrical networking model was developed to conduct parameter studies that identified the key cell electrical properties contributing to networking losses. The multi-chip module (MCM) approach (Figure 12) allows the selective assembly of cells into modules which can reduce networking losses. A second technique that improved module electrical performance was changing the assembly technique used to attach the electrical interconnects to the cell busbar. Microwelding, a direct bond technique (i.e., gold-to-gold), replaced a solder technique. This eliminated a consistent degradation to cell shunt resistance, which in turn had reduced module electrical fill factor by $5 \%$ when compared to cell fill factor. Currently, there is no measurable degradation in cell performance when assembled into a module.

3) Improved yield

The primary increase in yield was achieved by using the direct bond technique for the cell frontsurface electrical interconnects discussed above. This eliminated a reduction in yield associated with solder shorting the PN junction along the edge of the cell, below the cell busbar.

In summary, significant improvement in TPV module performance was achieved by minimizing performance losses associated with TPV module design and assembly. These techniques were developed 
and proof-tested on our small modules (i.e., $\left.1-4 \mathrm{~cm}^{2}\right)$. The fabrication of our larger $\left(\sim 100 \mathrm{~cm}^{2}\right)$ modules employs the same techniques with only slight modifications to accommodate the larger dimensions.

\section{Efficiency Measurements}

Other than building and testing full-scale systems, the most reliable determinations of TPV conversion efficiency are derived from direct measurements of small integrated module specimens tested under prototypic conditions. Measurements of conversion efficiency reported here are based on such experiments carried out on small $\left(1-4 \mathrm{~cm}^{2}\right)$ specimens in our PCT system and larger $\left(\sim 100 \mathrm{~cm}^{2}\right)$ specimens carried out in our SAT system. These hardware sets are comprised of all components that would be found in full-scale units. Unlike photovoltaic systems which base efficiency measurements on the total incident power, the convention in TPV systems is to base efficiency measurements on the total absorbed power:

$$
\eta_{T P V}=\frac{P_{\max }}{P_{\max }+P_{r e j}}
$$

where: $\mathrm{P}_{\max }$ is the peak (load matched) power output

$\mathrm{P}_{\text {rej }}$ is the parasitic absorbed power

The Photonic Cavity Test (PCT) System is shown in Figure 3a. It was developed to provide an optically prototypic environment in which the performance of small modules would accurately mimic the behavior of larger-scale units. To achieve this end, the test system:

Models the flat-plate geometry we envision for larger units

Includes a large, graybody radiator (SiC)

Explicitly incorporates geometric effects, isotropic incident radiation, photonic recuperation Is run at prototypic radiator temperatures

Furthermore, all testing was carried out under vacuum conditions to improve the reliability of the results by eliminating spurious convective heat loss mechanisms. Modules were tested in the PCT system under steady-state conditions. The maximum power point (i.e., the numerator in Equ. 7) was determined from the module I-V curve. Figure 13 is a typical I-V curve for a four cell (in series) array. The heat absorption rate (i.e., the denominator in Equ. 7) was measured from the temperature gradient developed in the copper pedestal to which the module is bonded (Fig. 3a). Measured conversion efficiency is the ratio of these two terms.

The major non-prototypic characteristic of the PCT is the "gold shield enhancement effect". Because the small module is surrounded by highly reflective shields (rather that other modules), the above-bandgap incident radiation and the measured power density are artificially increased. Detailed monte carlo and ray tracing analyses have shown that this effect increases power by $8 \%$ for our typical conditions. Effects on measured efficiency are small. All power density values reported here have been reduced by $8 \%$ to account for the "gold shield enhancement effect".

Figure 14 presents the results of efficiency measurements and Figure 15 shows the measured power density results for two recent TPV modules. Table 2 provides more detailed information in tabular format. Module \#25 was a 1 $\mathrm{cm}^{2}$ specimen with two cells (in series) and a front surface filter for spectral control. Module \#47 was a $4 \mathrm{~cm}^{2}$ specimen with eight cells (series/parallel configuration) of similar design.

The Small Array Test (SAT) System is shown in Figure 3b. Like the PCT, this system tests integrated hardware in a prototypic environment The larger system was designed and fabricated to address several issues not included in the PCT:

The effect of non-uniform radiant illumination on the cell array The impact of a large-scale cell networking on electrical output The effect of cell variation on electrical output

The problems associated with fabrication of a larger (25X) TPV array 
The fabrication of the $100 \mathrm{~cm}^{2}$ array proved to be tedious but no unforeseen problems were encountered. The array was comprised of 192 cells $(1.0 \mathrm{~cm}$ x $0.5 \mathrm{~cm})$ arranged in eight series-connected columns of 24 cells each; each symmetric column pair was externally connected to increase the output voltage to about 12 volts. Because of small gaps between cells, the total array area was $8.3 \mathrm{~cm} \mathrm{x} 12.3 \mathrm{~cm}$. To improve illumination uniformity, a $5 \mathrm{~mm}$ wide gold apron was added to the outside perimeter of the array. Figure 16 is a schematic diagram of the module layout.

The overall conversion for this plate was $12.5 \%$ which is significantly less than the $20 \%$ measured in the PCT tests. Part of the reason for the lower efficiency is the quality of the cells. For example, if Module \#47 had been fabricated from similar quality cells, the efficiency would probably have been about $18 \%$. Other factors reducing conversion efficiency are:

Small cracks between cells (approx 6\% of total array area)

Non-uniform illumination of the cells

Cell mismatch (i.e., electrical networking effects)

Extraneous heat losses to the cold plate (radiative \& conductive)

Results for the SAT-1 module are also included in Table 2, below.

\begin{tabular}{|c|c|c|c|}
\hline \multicolumn{4}{|c|}{$\begin{array}{c}\text { TABLE } 2 \text { - Results of Measurements in Photonic Cavity Test (PCT) System - Lockheed Martin } \\
\text { TPV Modules \#25, \#47 } \\
\text { and Small Array Test (SAT) System -Lockheed Martin TPV Modules SAT-1 }\end{array}$} \\
\hline & \multicolumn{2}{|c|}{$\underline{\text { PCT System }}$} & \multirow{2}{*}{$\begin{array}{c}\underline{\text { SAT System }} \\
\text { Module SAT-1 }\end{array}$} \\
\hline Parameter & $\underline{\text { Module \#25 }}$ & Module \#47 & \\
\hline Dimensions & $1 \mathrm{~cm} \mathrm{X} \mathrm{1cm}$ & $1.89 \mathrm{~cm} \mathrm{X} 1.99 \mathrm{~cm}$ & $8.3 \mathrm{~cm} \times 12.3 \mathrm{~cm}$ \\
\hline Radiator Temp (C) & 953 & 956 & 955 \\
\hline Cell Temp (C) & 23 & 22 & 22 \\
\hline Open Circuit Voltage (V/cell) & 0.306 & 0.311 & 0.291 \\
\hline Short Circuit Current $\left(\mathrm{A} / \mathrm{cm}^{2}\right)$ & 2.737 & 2.400 & 1.864 \\
\hline Fill Factor & 0.693 & 0.693 & 0.609 \\
\hline $\begin{array}{l}\text { Elect. Power Output }\left(\mathrm{W} / \mathrm{cm}^{2}\right) \\
\text { (corr. for shield enhancement effect) }\end{array}$ & 0.534 & 0.510 & 0.330 \\
\hline $\begin{array}{l}\text { Parasitic Power }\left(\mathrm{W} / \mathrm{cm}^{2}\right) \\
\text { (corr. for shield enhancement effect) }\end{array}$ & 2.23 & 2.10 & 2.33 \\
\hline Measured Conversion Efficiency & $19.3 \%$ & $19.5 \%$ & $12.4 \%$ \\
\hline
\end{tabular}

\section{Performance Modeling}

The performance of the TPV modules was predicted using in-house codes which are based on well known principles of semiconductor materials and optical behavior. These codes have been extensively benchmarked against small-scale testing of TPV hardware under prototypic conditions (Ref. 7). The calculations include detailed characterization data from each component and corrections for the complex behavior of the photonic cavity. 
Geometric effects (surface structures, etc.) are modeled as simple area fractions; detailed 3dimensional modeling is not included. Furthermore, angular-dependent effects (emissivity, reflectivity) are modeled with energy-weighted average values. Finally, the models incorporate an $8 \%$ radiation enhancement factor to account for the second-order effect of the gold shields which surround the TPV module. This effect is an artifice of the PCT test configuration and will not occur in a full-scale TPV unit.

Figure 4 is a comparison of the in-cavity test performance of several recent modules to the modeling predictions. As shown, these models routinely predict test results to about $+/-2 \%$.

\section{Effect of Cell Temperature on TPV Conversion Efficiency}

The performance of the TPV modules is dependent on the temperature at which the cells operate. At higher temperatures, the open circuit voltage and the fill factor will suffer primarily due to an increase in reverse (dark) current. Complicating the matter, the cell bandgap will shift to longer wavelengths which can disturb the compatibility between bandgap and filter "turn-on" wavelength. Figure 17 shows the sensitivity of efficiency to cell temperature for a recent Lockheed Martin module.

\section{References}

1. EJ Brown, PF Baldasaro, SR Burger, LR Danielson, DM DePoy, GJ Nichols, WF Topper, TD Rahmlow; 'The Status of TPV Energy Conversion Technology at Lockheed Martin Corp.'; Space Technology and Applications International Forum (STAIF); February 2, 2003

2. 'Silicon Photovoltaic Cells in TPV Conversion'; USAEC Contract AT(30-1)-3587; March 10, 1967

3. RM Swanson; ‘Final Report, Radiant Energy Conversion'; ER-1272 EPRI Research Project 790-2; December, 1979

4. JC Bass, NB Elsner, PH Miller; 'Nuclear Thermophotovoltaics’; $18^{\text {th }}$ IECEC Conf.; July, 1983

5. G.W. Charache, J.L. Egley, D.M. DePoy, L.R. Danielson, M.J. Freeman, R.J. Dziendziel, J.F. Moynihan, P.F. Baldasaro, B.C. Campbell, C.A. Wang, H.K. Choi, G.W. Turner, S.J. Wojtczuk, P. Colter, P. Sharps, M. Timmons, R.E. Fahey, K. Zhang, 'Infrared Materials for Thermophotovoltaic Applications,' J. Electron. Mater. 27, 1038-1042 (1998).

6. PF Baldasaro, EJ Brown, DM DePoy, BC Campbell, JR Parrington; “Experimental Assessment of Low Temperature Voltaic Energy Conversion"; First NREL Conference on Thermophotovoltaic Generation of Electricity; July, 1994

7. EJ Brown, CT Ballinger, GW Charache, LR Danielson, DM DePoy, TJ Donovan, M LoCasio; "Measurements of Conversion Efficiency for a Flat Plate Thermophotovoltaic System Using a Photonic Cavity Test System”; AIAA-2000-3029, The 35th IECEC Conf., Las Vegas, NV; July, 2000 
FIGURE 1 - Measured Conversion Efficiency for Small-Scale Modules at Lockheed Martin Corp.

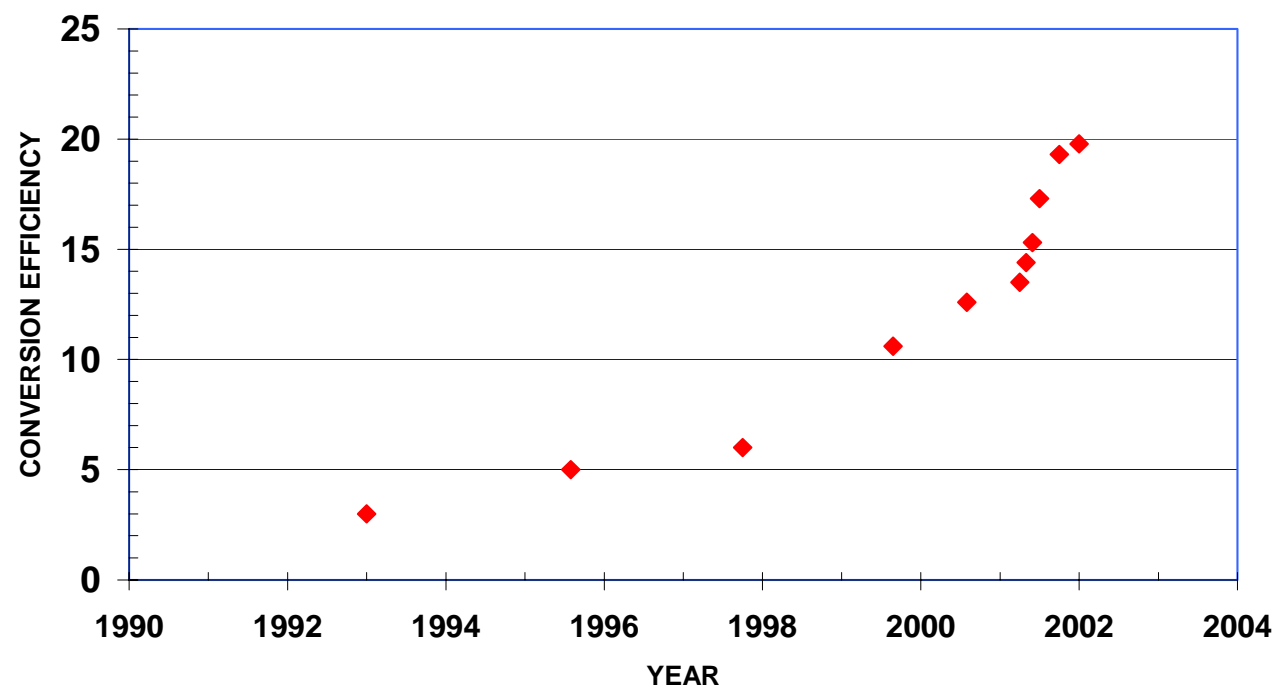

FIGURE 2 - TANDEM FILTER KX-23; LATEST LOCKHEED MARTIN DESIGN FOR $0.52 \mathrm{eV}$ DIODES

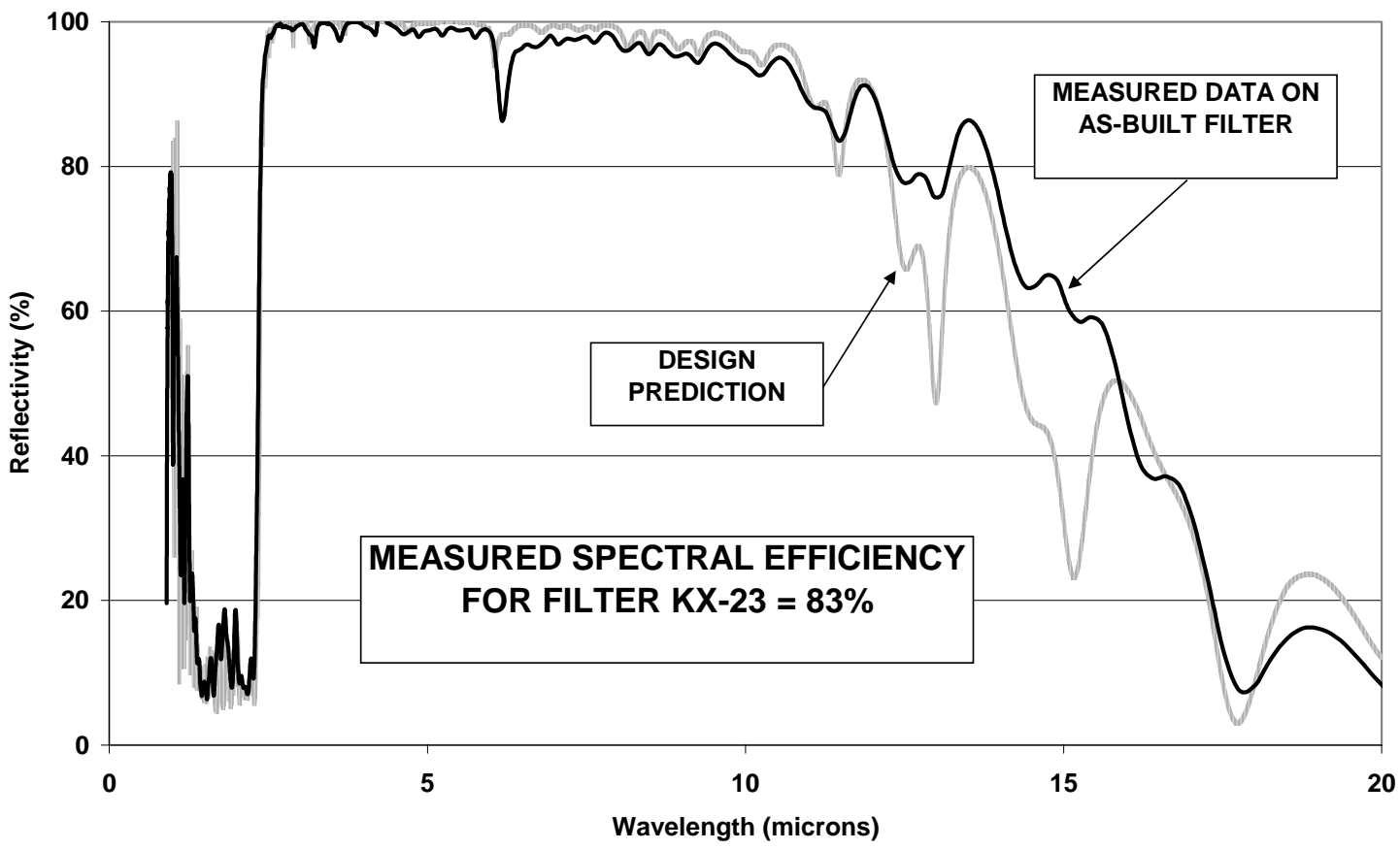



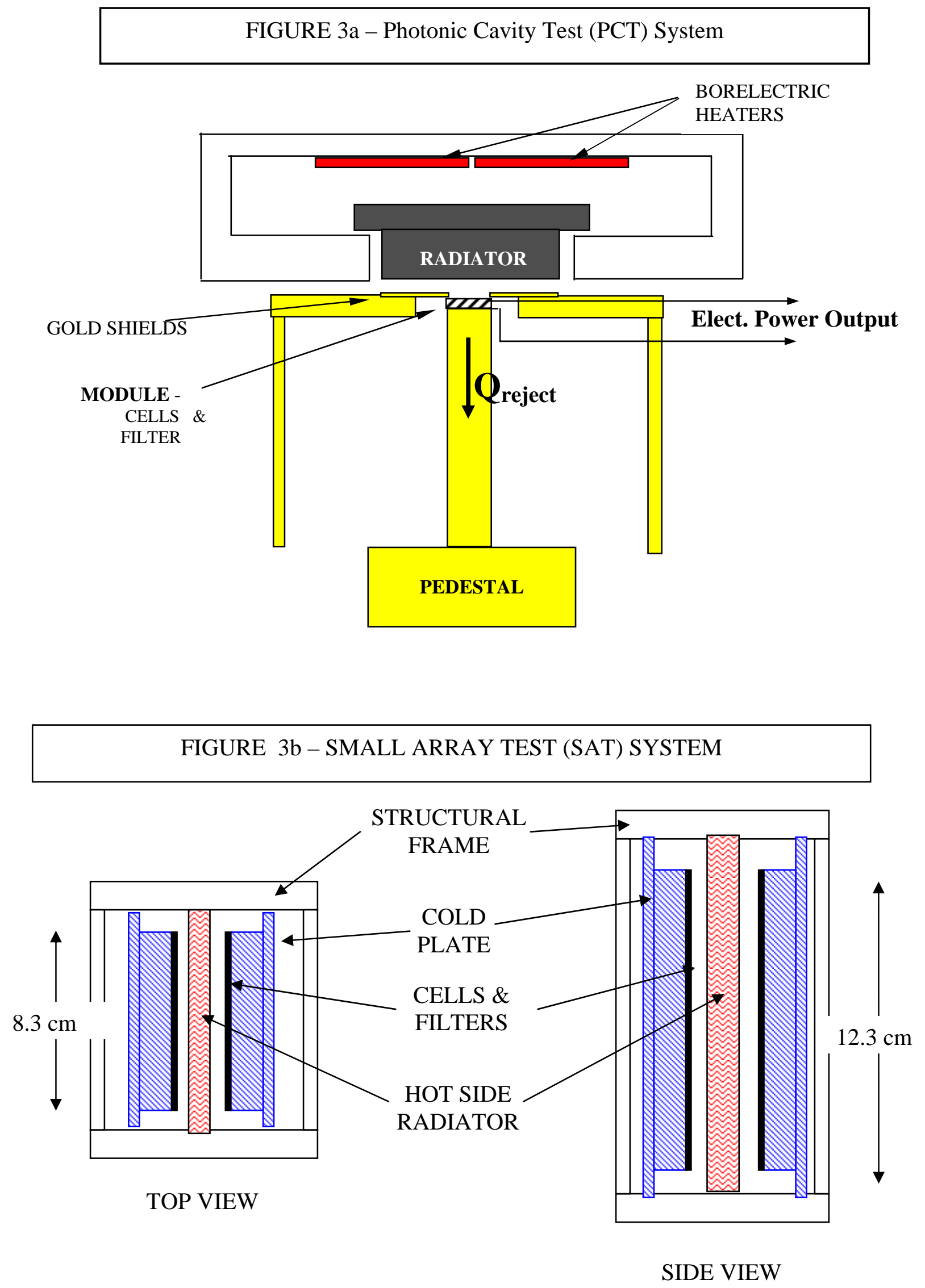


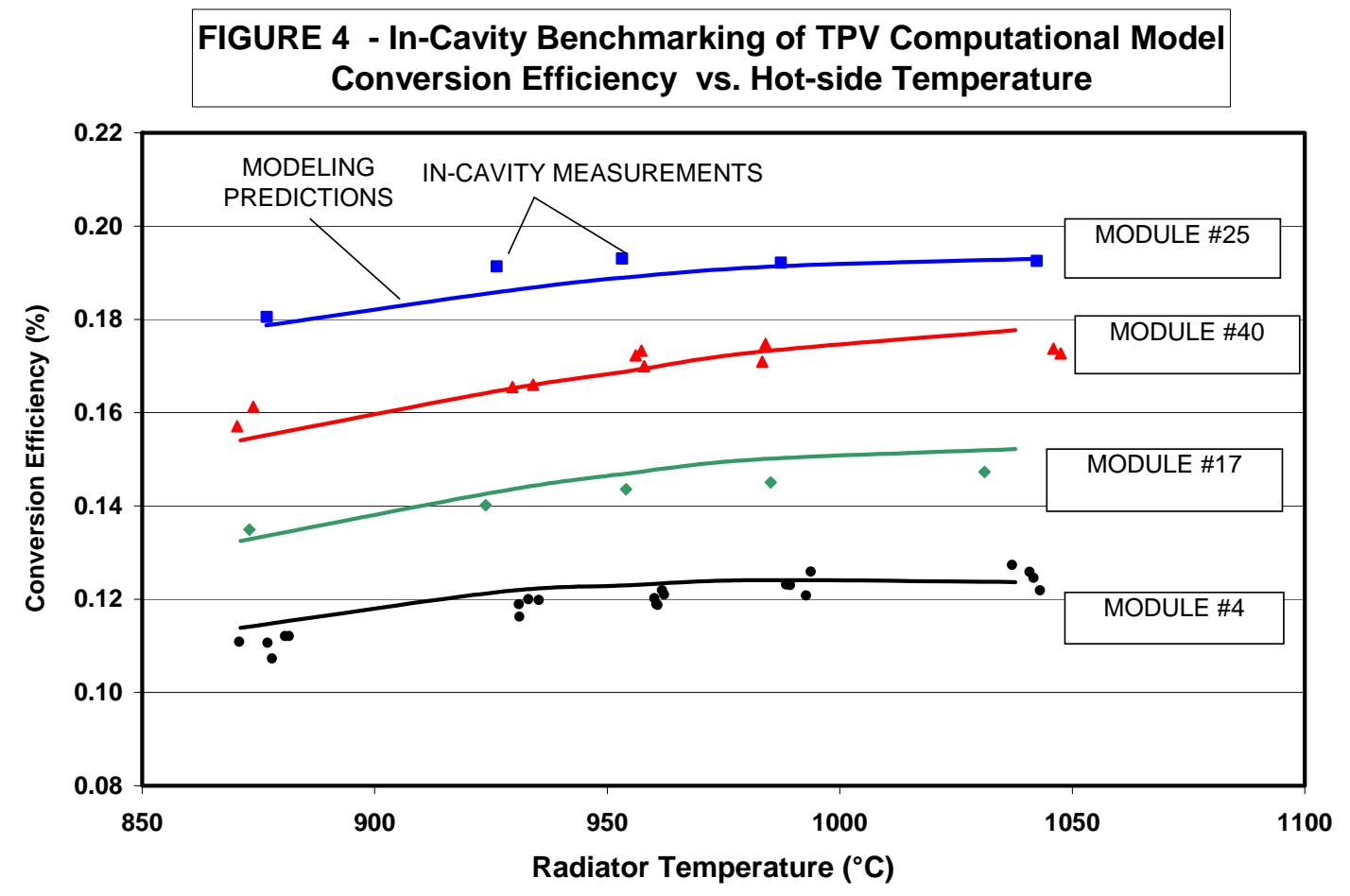

FIGURE 5- TPV direct energy conversion system with front surface filter for spectral control

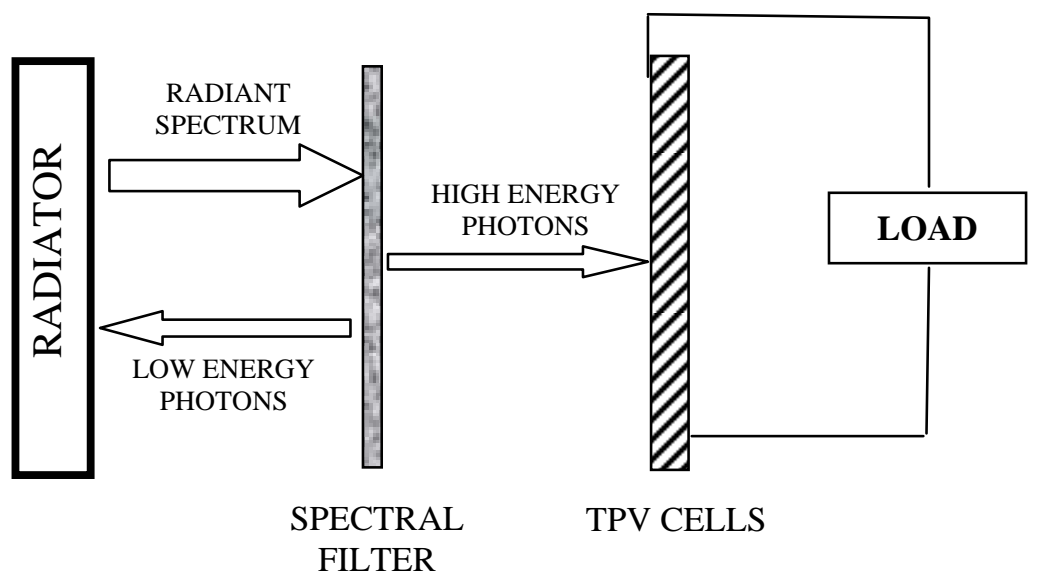


Figure 6 - Convertible Portion of a Blackbody Radiant Spectrum by a TPV Diode
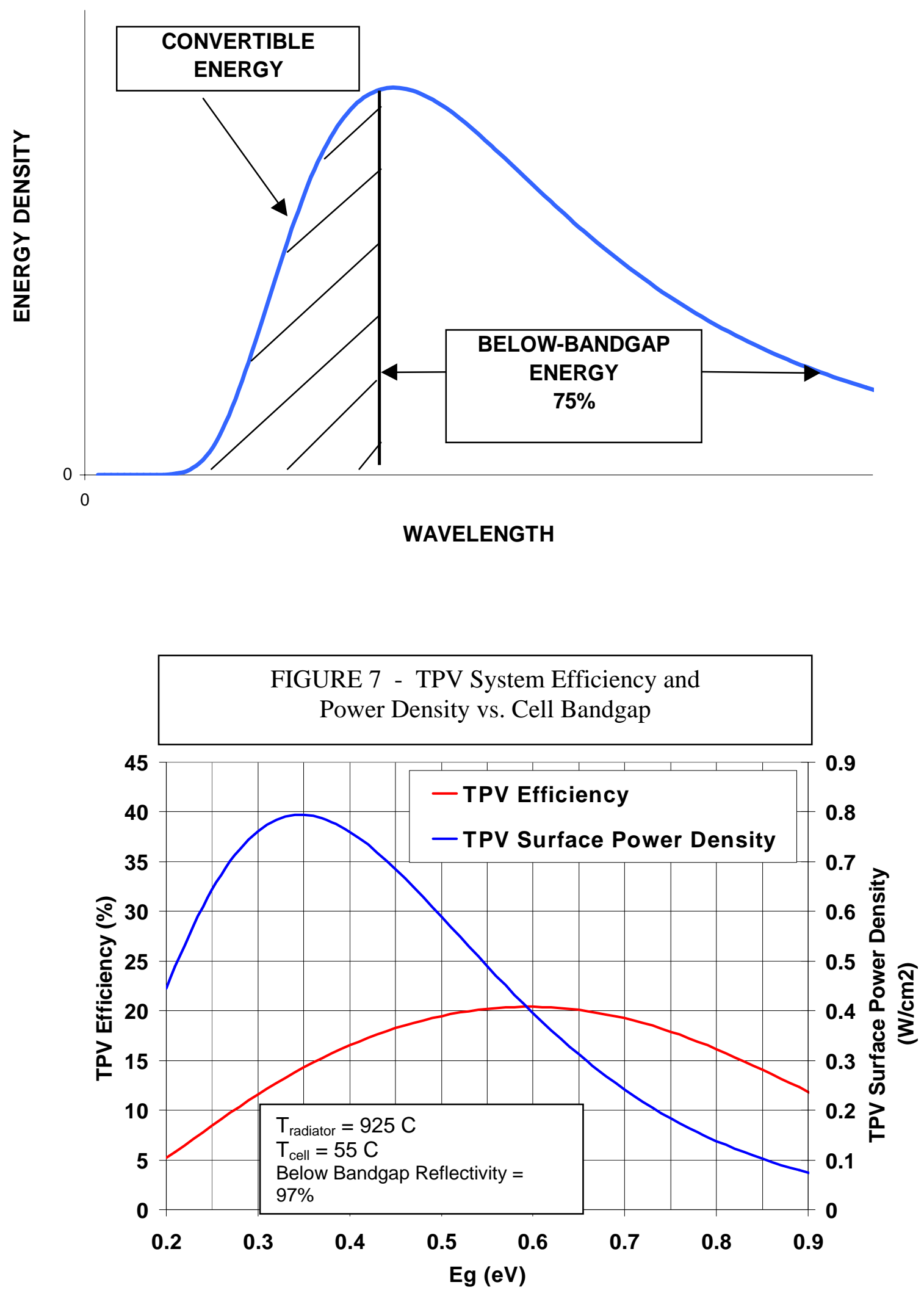

American Institute of Aeronautics and Astronautics 
FIGURE 8 - GaInAsSb TPV Device Layers with Metal Contacts

front contact metal grids

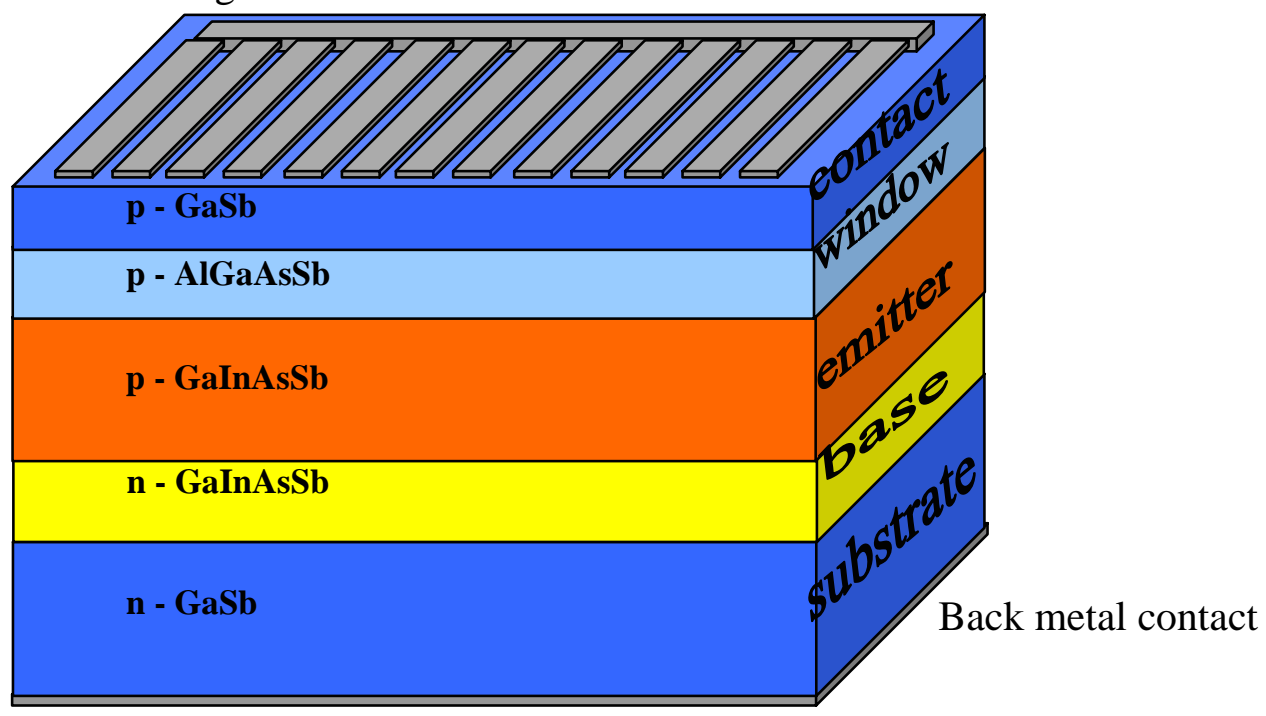

FIGURE 9 - Angle of Incidence Considerations for TPV Spectral Control Photon Distribution as a function of Angle of Incidence for Infinite Parallel Flat Plate Geometry

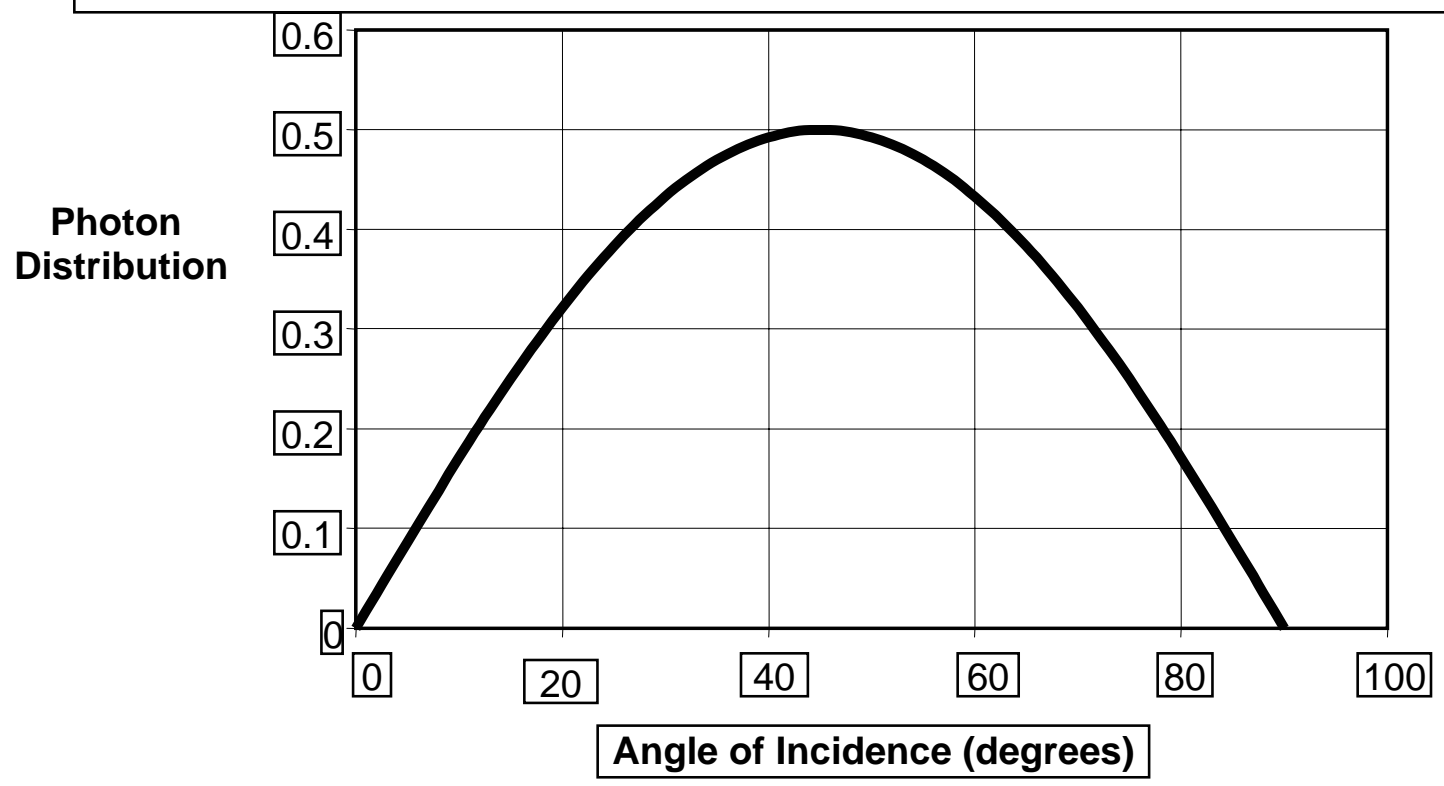

American Institute of Aeronautics and Astronautics 


\begin{tabular}{|c|}
\hline FIGURE 10 - Tandem Filter Concept \\
\hline Interference F ilter \\
\hline InPAs Plasma Filter \\
\hline InP S ubstrate \\
\hline Anti-Reflection C oating \\
\hline Optical Adhesive \\
\hline Anti-Reflection C oating \\
\hline TPV Cell \\
\hline
\end{tabular}

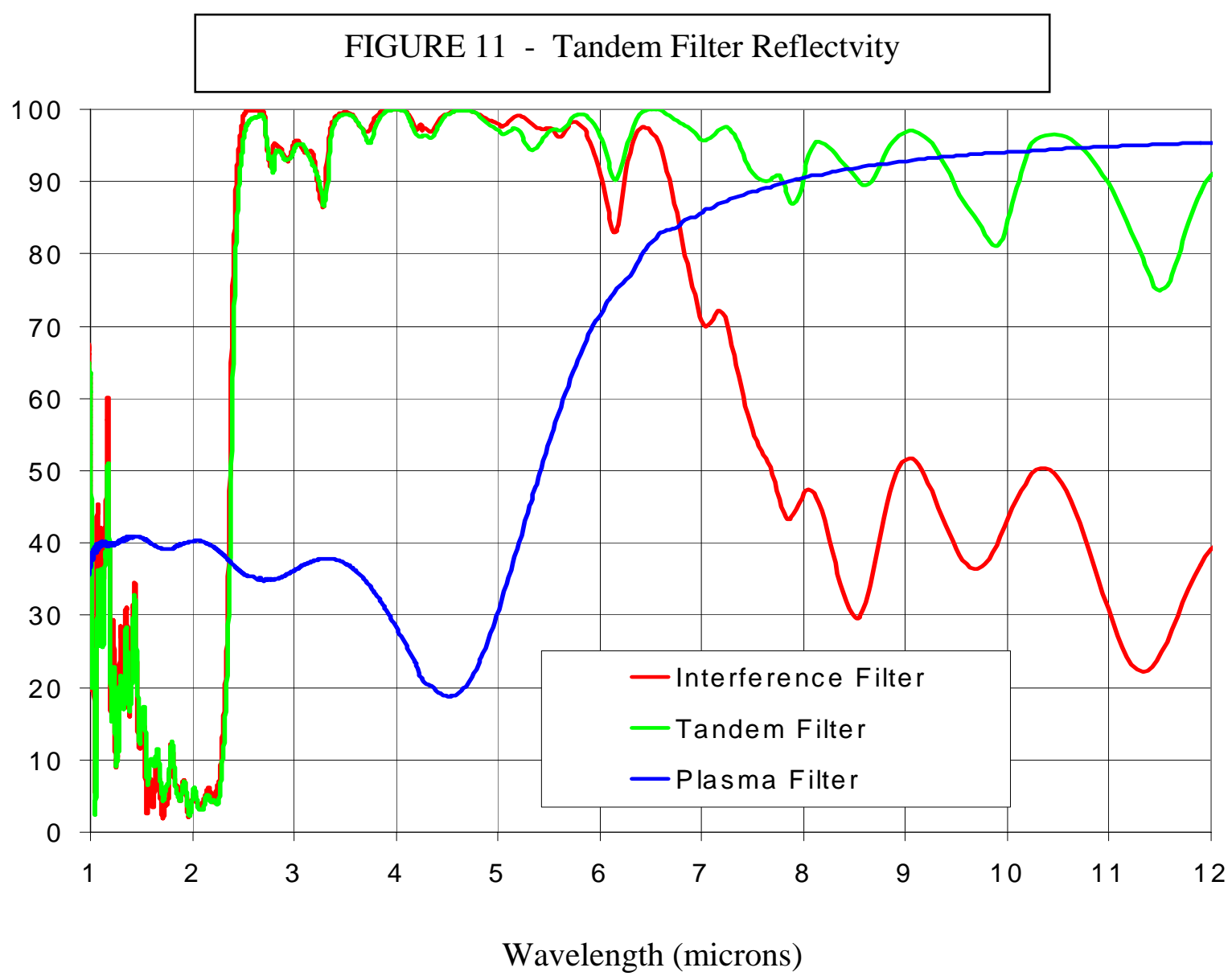



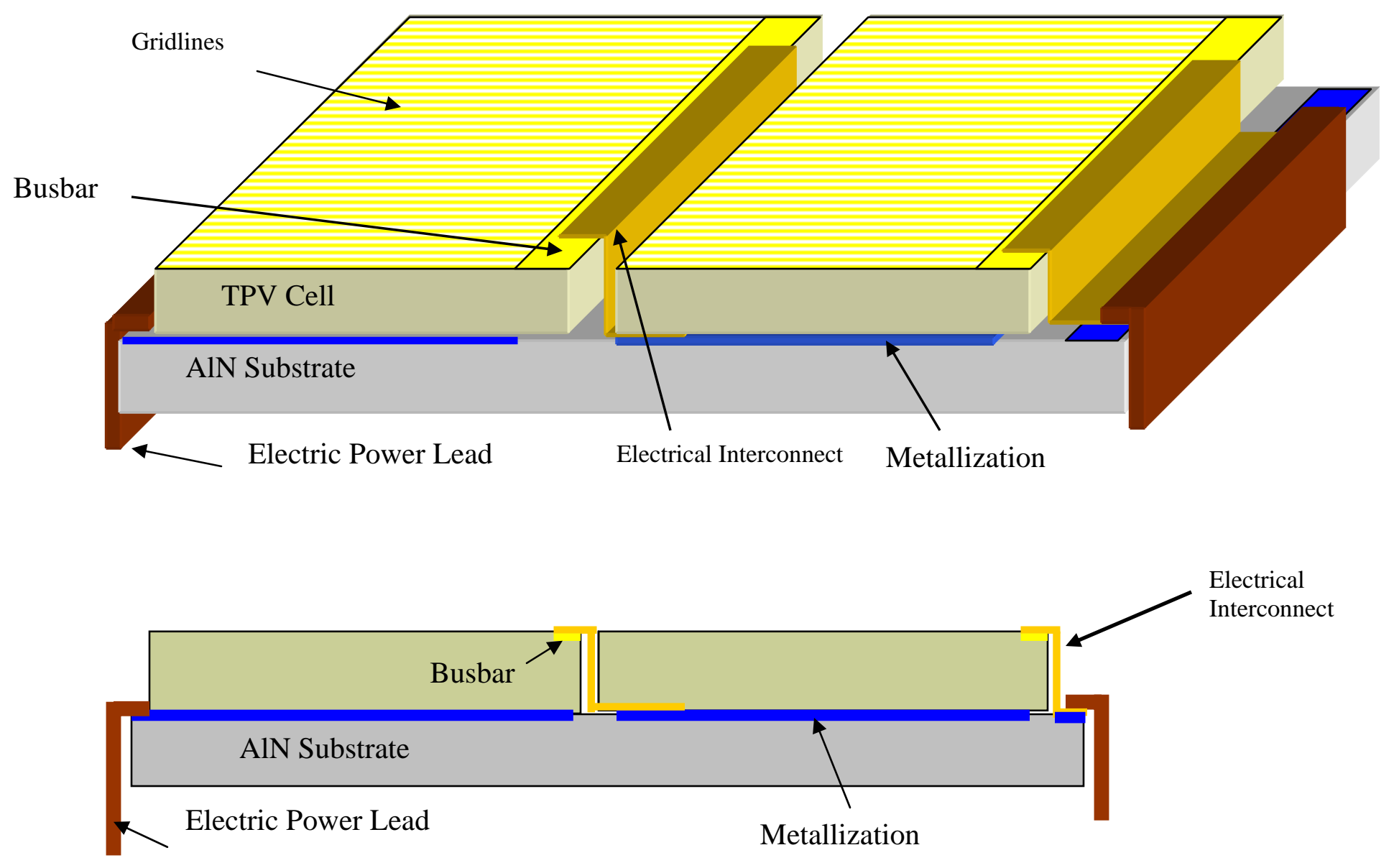

Figure 12. TPV Power Module Sketch 
FIGURE 13 - Typical TPV I-V Curve

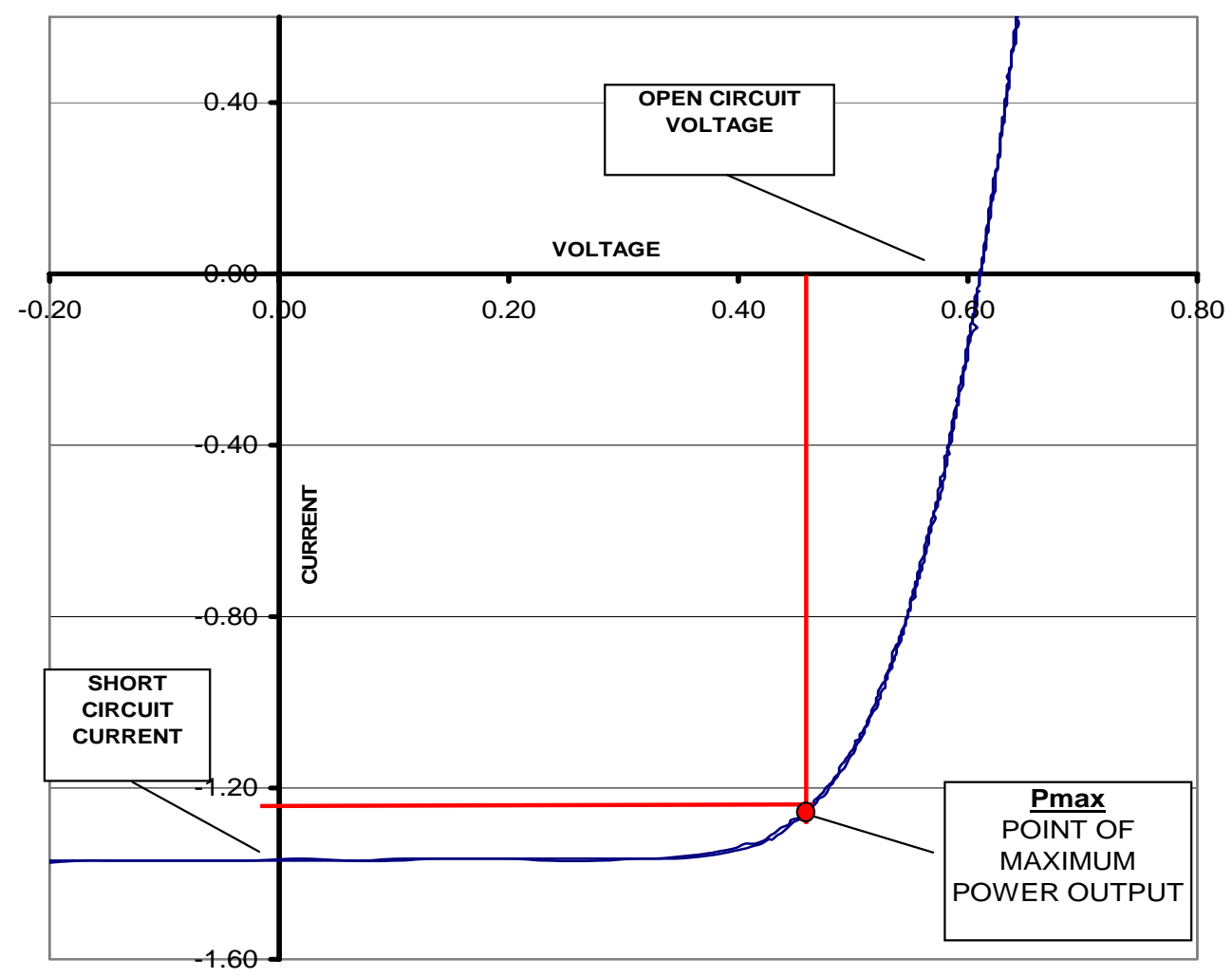

FIGURE 14 - PCT Measurements of Lockheed Martin TPV Modules Conversion Efficiency vs Radiator Temperature

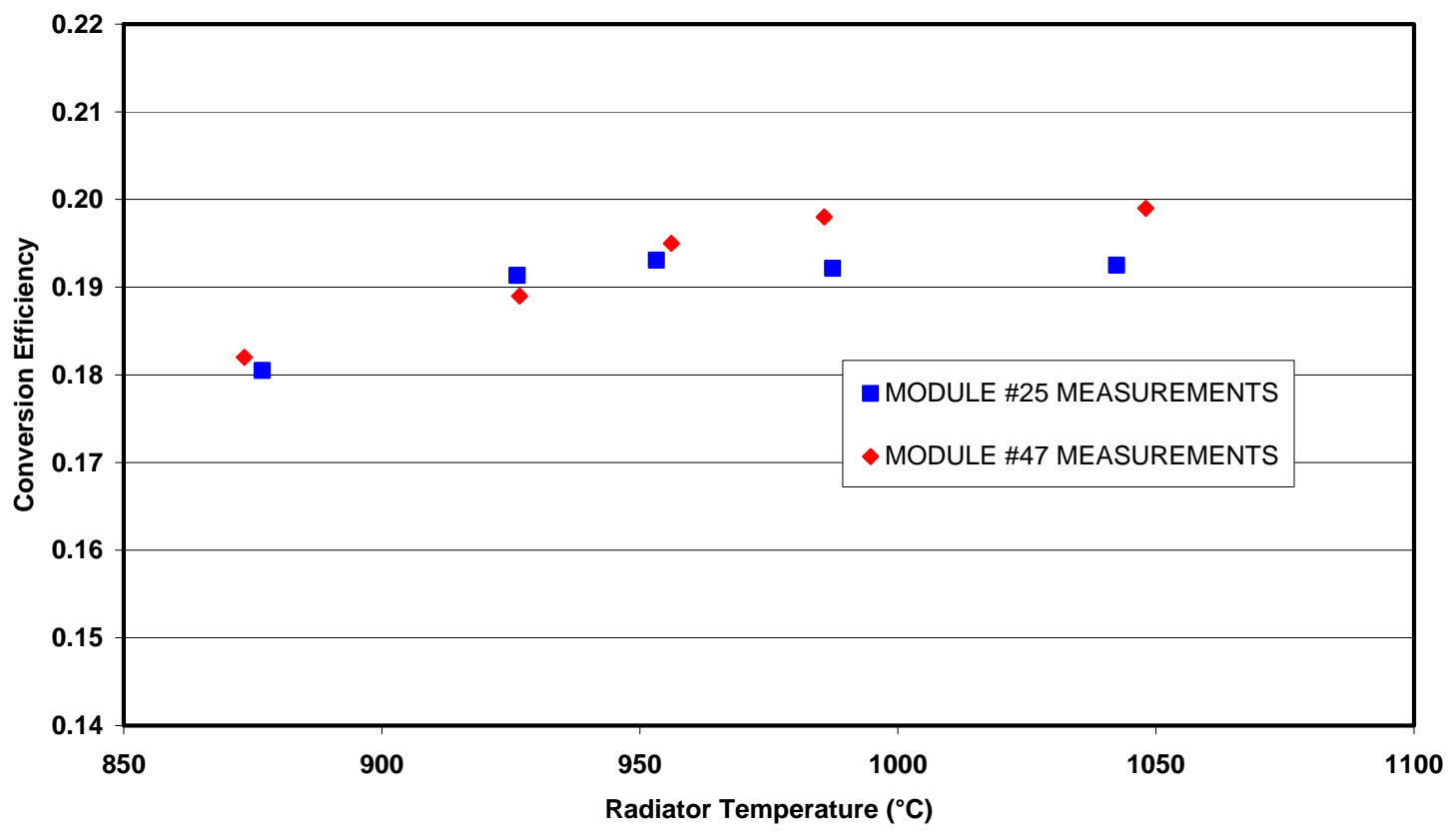

American Institute of Aeronautics and Astronautics 

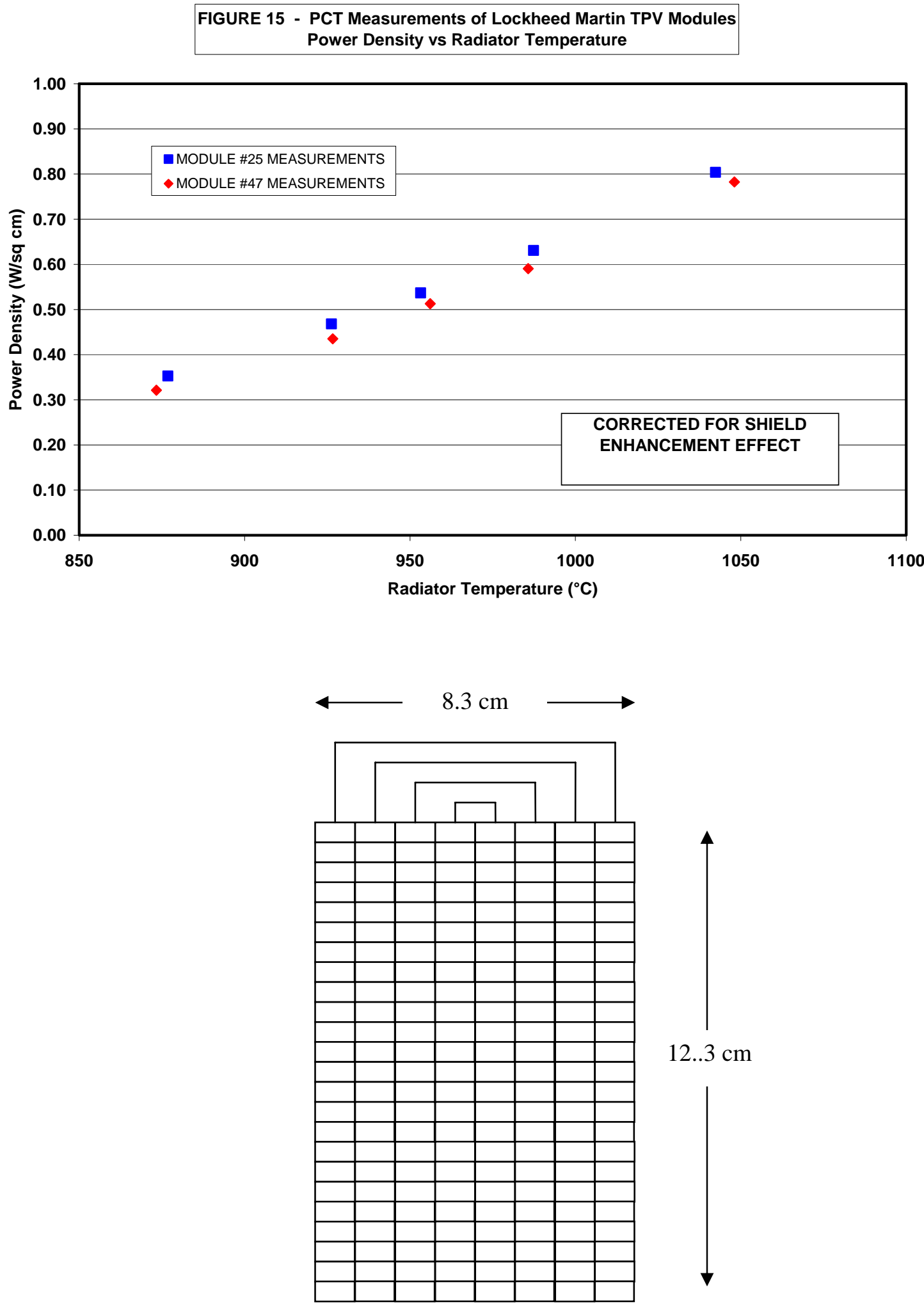

FIGURE 16 - Electrical Interconnect Pattern for the SAT Array 


\section{FIGURE 17 - Effect of Diode Temperature on TPV Conversion Efficiency}

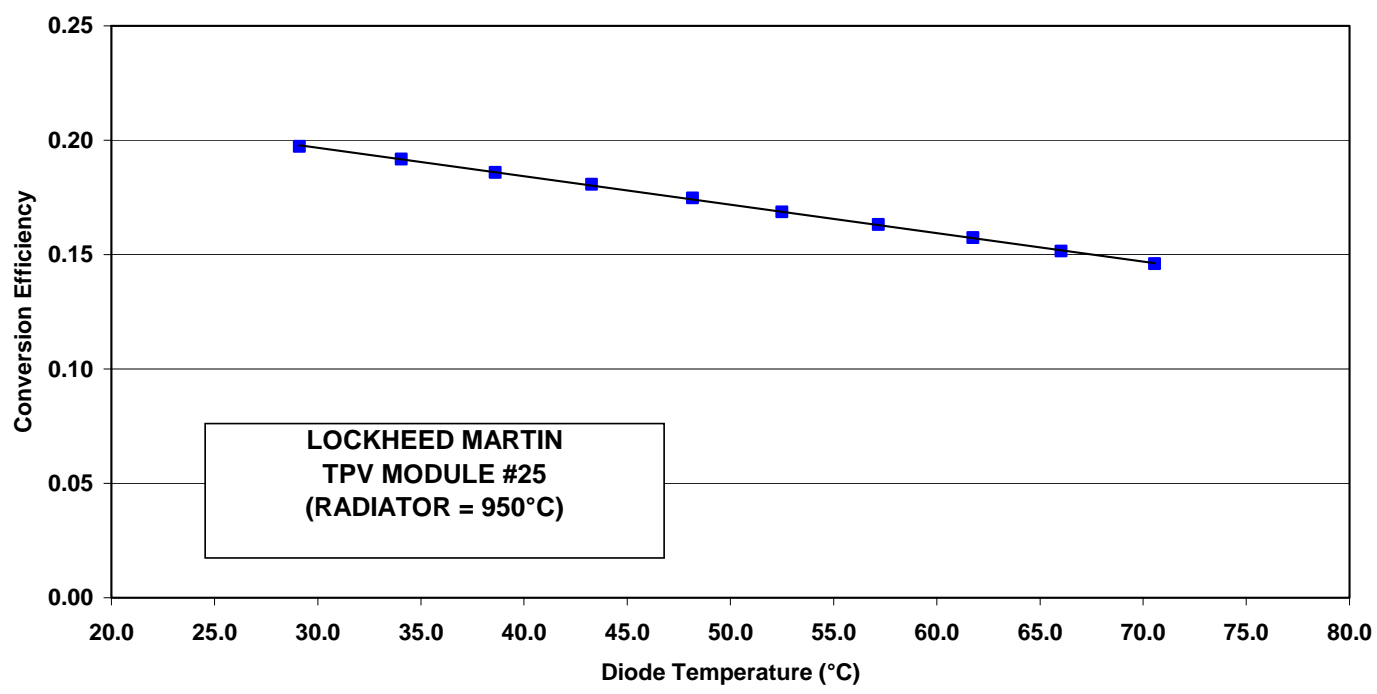

